Hum Genet (1990) $85: 581-586$

\title{
Direct carrier detection by in situ suppression hybridization with cosmid clones of the Duchenne/Becker muscular dystrophy locus
}

\author{
T.Ried ${ }^{1}$, V.Mahler ${ }^{1}$, P.Vogt ${ }^{1}$, L.Blonden ${ }^{2}$, G.J.B.van Ommen ${ }^{2}$, T. Cremer ${ }^{1}$, and M.Cremer ${ }^{1}$ \\ ${ }^{1}$ Institut für Humangenetik und Anthropologie der Universität, Im Neuenheimer Feld 328, W-6900 Heidelberg, \\ Federal Republic of Germany \\ ${ }^{2}$ Department of Human Genetics, Sylvius Laboratories, NL-2333 AL Leiden, The Netherlands
}

Received April 5, 1990 / Revised June 5, 1990

\begin{abstract}
Summary. A basic problem in genetic counseling of families with Duchenne/Becker muscular dystrophy (DMD/BMD) concerns the carrier status of female relatives of an affected male. In about $60 \%$ of these patients, deletions of one or more exons of the dystrophin gene can be identified. These deletions preferentially include exon 45 , which can be detected by multiplex polymerase chain reaction (PCR) and Southern blot analysis of genomic cosmid clones that map to this critical region. As a new approach for definitive carrier detection, we have performed chromosomal in situ suppression (CISS) hybridization with these cosmid clones in female relatives of four unrelated patients. In normal females, most metaphases showed signals on both $\mathrm{X}$ chromosomes, whereas only one $\mathrm{X}$ chromosome was labeled in carriers. Our results demonstrate that CISS hybridization can define the carrier status in female relatives of DMD patients exhibiting a deletion in the dystrophin gene.
\end{abstract}

\section{Introduction}

The gene responsible for Duchenne/Becker muscular dystrophy (DMD/BMD) maps to Xp21 and is the largest human gene known so far. At least 65 exons coding for an mRNA of $14 \mathrm{~kb}$ are distributed within a region of $2.3 \mathrm{Mb}$ (for review see Love and Davies 1989). Recently, the coded protein, called dystrophin, has been identified. It is localized at the cytoplasmic face of the plasma membrane of the muscle fibers. In DMD patients, no dystrophin can be detected in muscle tissue using antibodies against defined regions of dystrophin (Hoffman et al. 1987; Koenig et al. 1988; Bonilla et al. 1988), whereas BMD patients usually show an altered molecular weight of dystrophin (Arahata et al. 1989).

Within the dystrophin gene deletions that lead to the disease phenotype can be detected in about $60 \%$ of DMD

Offprint requests to: $\mathrm{M}$. Cremer patients (Koenig et al. 1989; Den Dunnen et al. 1989). Approximately $60 \%$ of these deletions include exon 45 and occur in the region defined by the probe P20 (Wapenaar et al. 1988).

About one third of all DMD patients arise by new mutations. In the remainder, the mutation has occurred in one of the germ cells that formed the zygote in an earlier generation. This situation results in a high carrier risk for the mother and other female relatives of an affected boy (Davie and Emery 1978).

In addition to clinical investigations (for review see Moser 1984), there are several biochemical and molecular approaches for carrier detection. All these approaches have their limitations (see Discussion). We have developed a direct approach that enables us to define unequivocally the carrier status of female relatives from patients exhibiting a deletion. This approach is based on the site-specific hybridization of cosmid clones using chromosomal in situ suppression (CISS) hybridization (Landegent et al. 1987; Lichter et al. 1990; Kievits et al. 1990). Here, we used three cosmid clones spanning the region around exon 45 (Fig. 1). Using a clone containing a DNA region that is deleted in the patient, carriers are expected to show a signal in Xp21 only on one of their X chromosomes, whereas in non-carriers both of the X chromosomes should exhibit a hybridization signal.

\section{Families and methods}

\section{Families}

Four possible carriers (probands) of the dystrophin gene were investigated in four independent families $A, B, C$ and $D$ (Fig. 2). In each of these families, the diagnosis of DMD or BMD was confirmed by the presence of a DMD-CDNA deletion detected by a multiplex PCR analysis in the affected boys. In family A, the patient (A3) expressed a dystrophin of reduced molecular weight supporting the diagnosis of BMD, in agreement with a mild clinical course of the disease. Dystrophin was absent in the patient (C3) of family $\mathrm{C}$, indicating DMD. D4 is a BMD patient with a dystrophin 


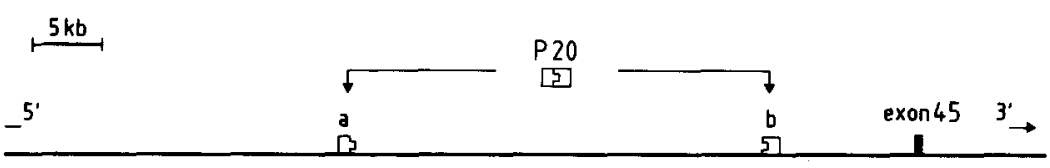

CPT 4 CAL 24
Fig. 1. Localization of cosmid clones $c P T 1$, cAL24 and $c P T 4$ in the $P 20$ subregion of the DMD gene (for further details see Blonden et al. 1989) of reduced weight and abundance. In the patient (B8) of family B, dystrophin was not investigated. In this family, DMD was evident by the clinical course and pedigree analysis. Three healthy non-related women not carrying a detectable dystrophin gene deletion and an obligate carrier of family B (B4, as indicated by pedigree analysis) served as controls.

\section{Methods}

Multiplex PCR-analysis. The nine primer pairs described by Chamberlain et al. (1989) and an additional primer pair (Speer et al. 1989) were used for amplification of $200 \mathrm{ng}$ of template DNA according to the protocol of Chamberlain et al. (1989) with the following modifications: 25 cycles using 2.5 units CETUS Taq-polymerase were performed and no DMSO was added. Amplification products were separated on a $3 \%$ NuSieve agarose gel (Seakem) in $1 \times$ TBE buffer.

DNA-Probes. DNA from the three cosmid clones cPT1, cAL24, cPT4 (Blonden et al. 1989, see also Fig. 1) and from the plasmid pXBR containing human X centromer-specific alphoid repeat (Yang et al. 1982) were prepared according to standard procedures (Maniatis et al. 1982). Probes were labeled by nick-translation substituting dTTP by Biotin-11-dUTP (Sigma) as described by Langer et al. (1981). A phage DNA library established from sorted human X chromosomes was purchased from ATTC (catalog no.: 57750) and labeled by nick-translation with Digoxigenin-11-dUTP (Boehringer Mannheim, FRG).

Cosmid hybridization of Southern-blots. Digestion of human genomic DNA with HindIII, gel electrophoresis and Southern blotting were performed following standard procedures. Labeling of cosmid probe DNA with random priming and competitive hybridization were carried out as described (Blonden et al. 1989).

Chromosome preparation and CISS-hybridization. Metaphase spreads from PHA-stimulated human lymphocytes were fixed with acetic acid/methanol $(1: 3 \mathrm{v} / \mathrm{v})$ and stored until use at $-80^{\circ} \mathrm{C}$. CISS-hybridization of biotinylated cosmid clones was carried out as described by Lichter et al. (1990). In experiments using a single cosmid clone, $200 \mathrm{ng}$ labeled cosmid DNA, $2 \mu \mathrm{g}$ sonicated human placenta DNA for competition and $8 \mu \mathrm{g}$ sonicated salmon sperm DNA (Sigma) were added to $10 \mu$ l hybridization mixture (sufficient for an area of $18 \times 18 \mathrm{~mm}$ ) containing $50 \%$ formamide (Fluka), $10 \%$ dextran sulfate and $1 \times \mathrm{SSC}$. In other experiments, all three cosmid clones were combined using $100 \mathrm{ng}$ of each labeled probe. When co-hybridization with pXBR was performed, $20 \mathrm{ng}$ probe DNA in $1 \mu \mathrm{l}$ hybridization mixture were added to the cosmid probe after the preannealing step (Cremer et al. 1988). Hybridized probes were detected with fluorescein-conjugated avidin (Vector Laboratories). The signal was amplified once using a biotinylated anti-avidin antibody (Vector Laboratories) and subsequent detection with fluorescein-conjugated avidin (Pinkel et al. 1986). For co-hybridization of the whole X-library, $400 \mathrm{ng}$ digoxogenin-labeled total phage DNA from this library and $100 \mathrm{ng}$ of each biotinylated cosmid was used. The signals were detected with a TRITCconjugated anti-digoxigenin antibody (Boehringer Mannheim) and the subsequent detection of the cosmid clones using avidin-conjugated to FITC and one amplification step (see above). Fluores-
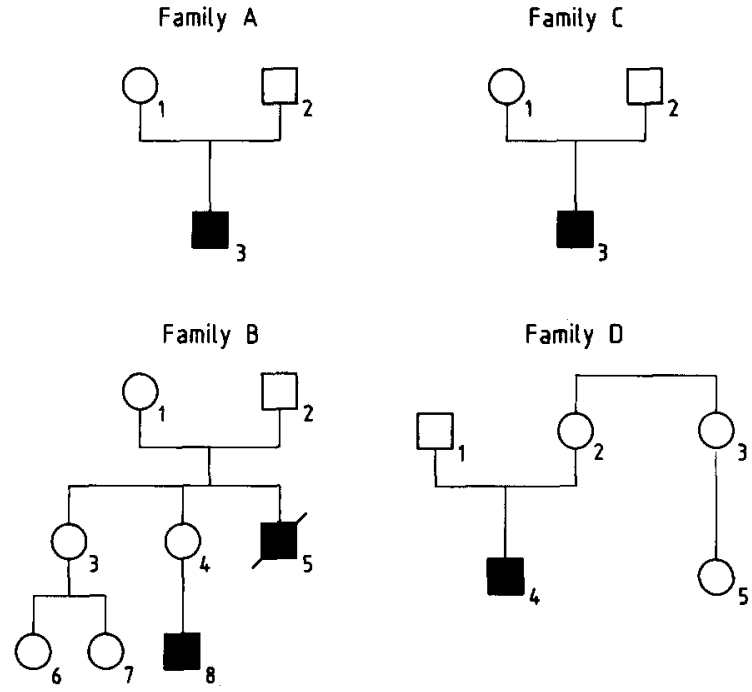

Fig. 2. Pedigrees of families A, B, C and D

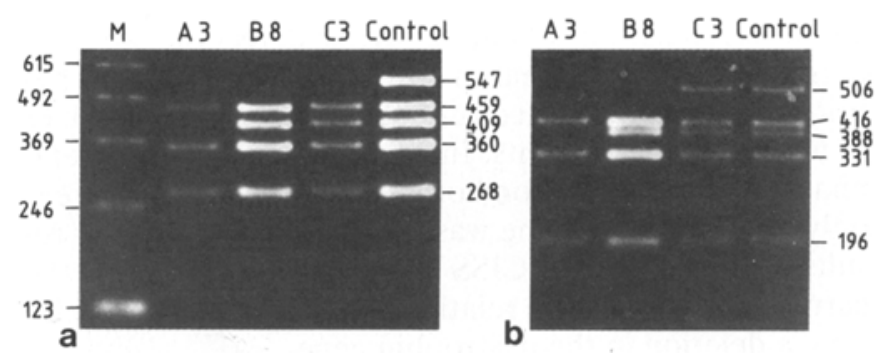

Fig. 3a,b. Multiplex DNA amplification of genomic DNA from patients $A 3, B 8$ and $C 3$. Amplification products in a represent exons 45 (547 bp-band), 19 (459 bp), 51 (409 bp), 8 (360 bp) and 44 (268 bp) of the dystrophin gene, and in b represent exons 48 (506 bp), 17 (416 bp), 51 (388 bp), 12 (331 bp) and 4 (196 bp). Patient $A 3$ presents a deletion of the dystrophin gene from exon 45 to at least exon 52 , patient $B 8$ from exon 45 to 51 and patient $C 3$ only for exon 45. As a control, DNA from a normal male was amplified. We used a 123-bp ladder $(M)$ as size marker

cence microscopy was performed with a Zeiss Photomikroskop III equipped for epifluorescence. Photographs were taken on an Agfachrome $1000 \mathrm{RS}$ color slide film.

\section{Results}

The DNA of patients A3, B8 and C3 (Fig. 2), screened for a deletion using the multiplex PCR-primer system (Fig. 3), shows the loss of exon 45 of the dystrophin gene. To determine whether the deletion around exon 45 extends at least the length of the cosmid cPT1 (Fig. 1), 


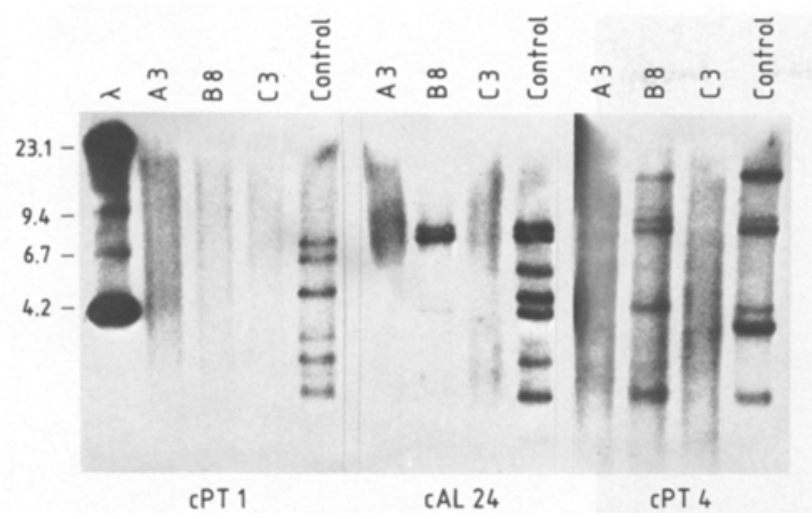

Fig. 4. Southern-blot hybridization of HindIII-digested DNA of DMD/BMD patients with the cosmid clones $c P T 1, c A L 24$ and cPT4. The normal control shows the expected bands. Patients A3 and $C 3$ are deleted for all three cosmids, whereas patient $B 8$ is completely deleted for CPT1 and partially for $C A L 24$ and $c P T 4$

Southern blots from these patients were hybridized with the cosmids cPT1, cAL24 and cPT4 (Fig. 4). In patients $\mathrm{A} 3$ and $\mathrm{C} 3$, all three cosmid clones were deleted. In patient B8, only cPT1 was completely deleted, whereas the two other clones were partially deleted (Fig. 4). Based on these results, CISS-hybridization of metaphase spreads from the obligate carrier B4 and the possible carrier B3 were performed with the $\mathrm{CPT} 1$ clone, whereas the possible carriers $\mathrm{A} 2$ and $\mathrm{C} 2$ in the other two families were investigated by CISS-hybridization with either $\mathrm{CPT} 1$ or the pooled clones cPT1, cAL24 and cPT4, in order to improve the hybridization signal.

CISS-hybridization of the single or pooled cosmid clones to metaphase spreads from healthy non-related female individuals from three non-affected families resulted in specific signals on both X chromosomes in most metaphase spreads (Fig. 5a, Table 1).

As expected, in the obligate carrier B4, only on X chromosome was labeled by cPT1 in all metaphase spreads that exhibited specific signals with this probe. There was no case of a metaphase spread exhibiting label on both $\mathrm{X}$ chromosomes (Fig. 5b, Table 1). The co-hybridization of the repetitive centromere probe pXBR (Yang et al. 1982) was used to facilitate the identification of the deleted $\mathrm{X}$ chromosome (Fig. 5b). The same result was seen in her sister B3 (with a $50 \%$ a priori risk of being a carrier) and demonstrates unequivocally that she carries the same deletion (Table 1). This result thus enables the direct investigation of the carrier status of the daughters of B3 by the method of CISS hybridization. Moreover, CISS-hybridization with the pooled cosmids performed in the probands A2 and C2 also resulted in the specific labeling of one $\mathrm{X}$ chromosome only, establishing that both probands are carriers of the deleted $\mathrm{X}$ chromosome (Table 1).

After the investigation of the described three families had been completed, family $\mathrm{D}$ was included in this study. Patient D4 showed a deletion of exons $45-48$ by PCR reaction and a complete deletion of the cPT1 clone in Southern blot hybridization (data not shown). Using samples from his mother D2, a possible carrier, we performed cohybridization with an X-chromosome-specific library labeled with digoxigenin for rapid identification of the X chromosomes and the biotinylated $\mathrm{CPT} 1$ cosmid clone. D2 showed hybridization signals with $\mathrm{cPT} 1$ on both $\mathrm{X}$ chromosomes on metaphase spreads (Fig. 5c,d); Table 1) and in nuclei (Fig. 5e,f), suggesting that she does not carry the DMD mutation (for the possibility of germline mosaicism, see Discussion). Proband D3 (Fig. 2), however, referred to us for genetic counseling, could definitely be excluded as a carrier for this mutation (see Discussion).

\section{Discussion}

Because of the high proportion of new mutations, which are estimated to be about $30 \%$ in DMD/BMD patients, genetic counseling of female relatives provides a particular problem when the carrier status cannot be deduced by pedigree analysis alone. The usefulness of the present biochemical and molecular approaches of carrier detection is limited. An elevation of the level of creatine kinase (CK) in carriers was first described by Schapira et al. (1960). However, since only $70 \%$ of adult carriers have an elevated CK level, a normal CK value does not exclude carrierships (Moser 1984). Intragenic restriction fragment length polymorphisms (RFLPs) to identify the $\mathrm{X}$ chromosome segregating with the DMD mutation may be misleading because of possible recombinations between the site of a DNA marker and the mutation site (Bakker et al. 1986). In sporadic cases, the carriership of the mother as studied by RFLP analysis may be considered unlikely if a second healthy son carries the same X chromosome as his affected brother. Such an interpretation, however, may also be misleading because of the possibility of germline mosaicism (Bakker et al. 1989; Darras et al. 1988). In cases with a defined deletion, gene dosis analysis in Southern blots from maternal DNA provides a further possibility for carrier detection (Mao and Cremer 1989). Under routine laboratory conditions, however, it may be problematic to base the decision of the carrier status of a female relative solely on this type of analysis. A definite carrier diagnosis can also be achieved by the identification of size altered fragments detected by field inversion gel electrophoresis (FIGE), but may not yield unequivocal results if the deletions are small (Chen et al. 1988). In DMD families, immunostaining of muscle tissue by dystrophin antibodies has been successfully used only for the detection of carriers with elevated CK levels. In BMD families, the usefulness of immunostaining or immunoblotting for carrier detection has not been established so far (Arahata et al. 1989; Miranda et al. 1989).

In this study, we have demonstrated that CISS-hybridization of cosmid probes specific for a deleted subregion of a patient's dystrophin-gene can be used to investigate directly the presence of this subregion on one or both $\mathrm{X}$ chromosomes of female relatives. In cases where only one $\mathrm{X}$ chromosome shows a hybridization signal, this approach provides unequivocal evidence confirming the carrier status of these females, even if the CK or RFLP analysis is not informative. 

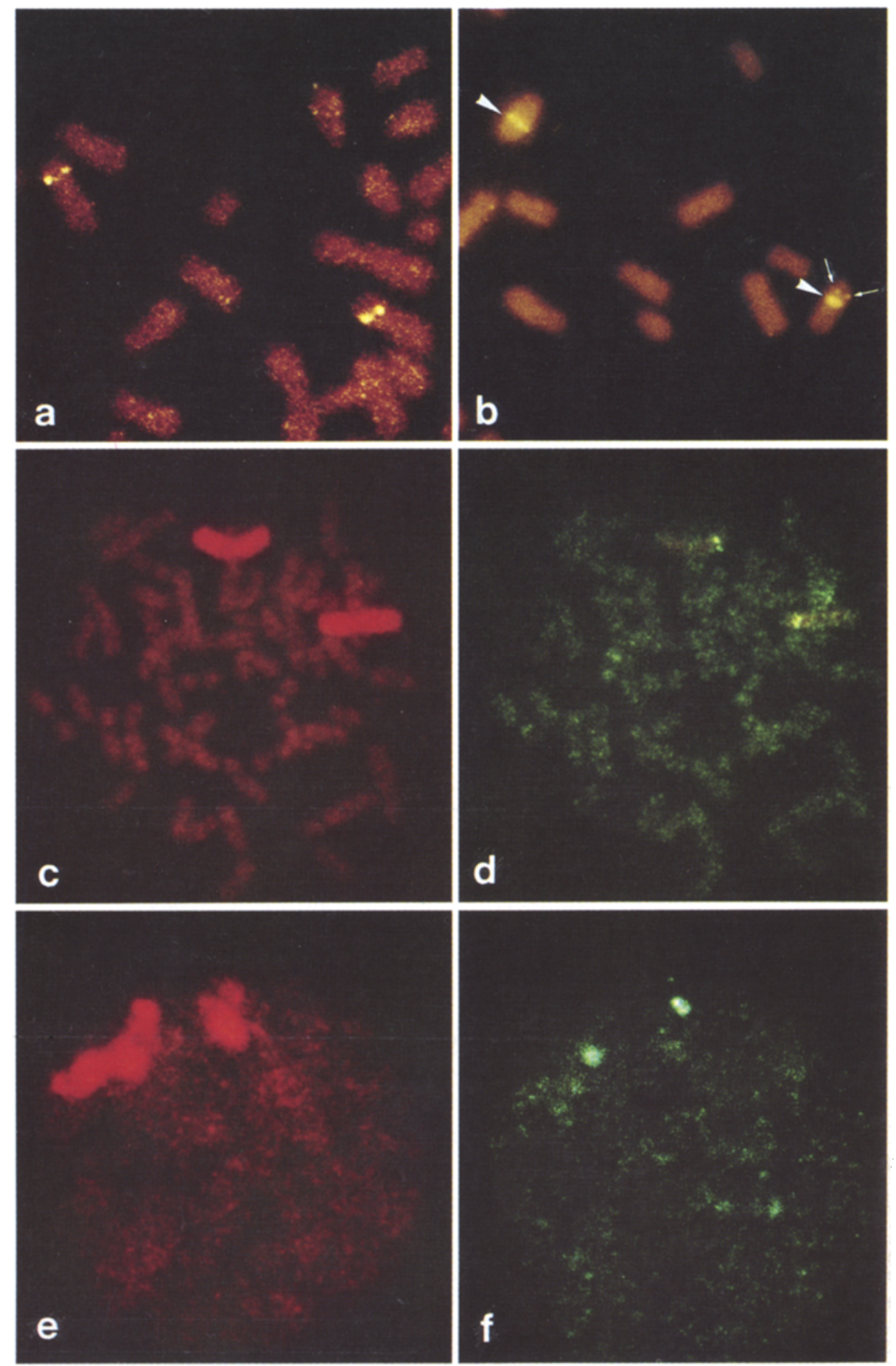

Fig. 5a-f. CISS hybridization of DMDspecific cosmid clones. a Metaphase spread of a normal female hybridized with the biotinylated cosmid CPT1 and counterstained with propidium iodide. On both X chromosomes, fluorescence signals are seen on both chromatids of the short arm. $\times 2000$. b Metaphase spread of an obligate carrier of family B (B4) after co-hybridization of the centromere-specific probe $\mathrm{pXBR}$ and $\mathrm{cPT} 1$. Chromosomes are counterstained with propidium iodide. The centromeres of both $\mathrm{X}$ chromosomes are delineated with $\mathrm{pXBR}$ (arrowheads). The cosmid signals on $\mathrm{Xp}$ are seen on one $\mathrm{X}$ chromosome (arrows) but not on the other. $\times 1500$.

c, $\mathbf{d}$ Metaphase spread of a possible carrier D1 after double hybridization with an $\mathrm{X}$-chromosome-specific library and cPT1. Both $\mathrm{X}$ chromosomes are delineated using a filter for rhodamine fluorescence (c). The cosmid signal is clearly seen on both $\mathrm{X}$ chromosomes with a filter for fluorescein. Even with this filter, the X chromosomes can be detected (d). $\times 2000$. e, $\mathbf{f}$ Hybridization signal on a prophase nuclei of the same patient. Rhodamine filter (e) and fluorescein filter (f). $\times 1400$
In cases where both $\mathrm{X}$ chromosomes contained in the somatic cells of a female relative show hybridization signals, the interpretation is more complicated because of the repeated observation of germline mosaicisms in the mother (Bakker et al. 1989; Darras et al. 1988). Accordingly, such a finding does not rule out unequivocally a recurrence risk for further pregnancies of the mother, and prenatal diagnosis should still be offered. For the same reason, sisters of the patients may possibly be carriers and should be investigated independently of the outcome in the mother. On the other hand, a normal re- sult in the somatic cells of a patient's mother would be sufficient to rule out the possibility of a carriership in her sisters.

Our approach is limited by the fact that deletions in the dystrophin gene can be detected so far in only $60 \%$ of the patients. In the families presented in this investigation, a deletion spanned at least the length of one cosmid clone, i.e., about $40 \mathrm{~kb}$. The progress of non-radioactive in situ hybridization techniques has made it possible to detect single-copy targets as small as $2-5 \mathrm{~kb}$ (Lichter et al. 1988; Cherif et al. 1989). Accordingly, all iden- 
Table 1. Evaluation of hybridization efficiency with the DMD-specific cosmid probes (only cPT1 or three cosmids as a pool). From each proband expect D1 (50), 100 metaphases were counted

\begin{tabular}{|c|c|c|c|c|c|}
\hline \multirow[t]{2}{*}{ Proband } & \multirow[t]{2}{*}{ Probe } & \multirow[t]{2}{*}{$\mathrm{N}$} & \multicolumn{3}{|c|}{ Hybridization signal } \\
\hline & & & Both X & One X & None \\
\hline A1 & Pool & 100 & 0 & 93 & 7 \\
\hline B3 & $\mathrm{cPT} 1$ & 100 & 0 & 94 & 6 \\
\hline B4 & $\mathrm{cPT} 1$ & 100 & 0 & 91 & 9 \\
\hline $\mathrm{C} 1$ & Pool & 100 & 0 & 92 & 8 \\
\hline D1 & $\mathrm{cPT} 1$ & 50 & 43 & 1 & 6 \\
\hline Normal & Pool & 100 & 85 & 2 & 13 \\
\hline \multirow[t]{2}{*}{ Females } & Pool & 100 & 91 & 1 & 8 \\
\hline & cPT1 & 100 & 89 & 2 & 9 \\
\hline
\end{tabular}

tifiable deletions more than $2 \mathrm{~kb}$ in size in the dystrophin gene should be accessible to this technique provided that the necessary clones become available for in situ hybridization. In families where the affected males have already deceased, in situ hybridization of probes defining deletion-prone subregions of the dystrophin gene may be directly used to screen potential carriers. Such an approach will become even more powerful following the development of multi color in situ hybridization techniques that allow the simultaneous staining of multiple gene targets in different colors (Nederlof et al. 1990). We expect that, in addition to the analysis of X chromosomes in metaphase spreads, DMD carrier detection will become possible in future by the analysis of multicolored hybridization signals directly in interphase nuclei.

Acknowledgements. We are indebted to M. Köhler for his help during the experimental stage. We thank P. Lichter, C. Lengauer, R. Keil, A. Jauch and S. Popp for discussions, K. Kilian for technical assistance and T. Voit for support in the search for appropriate families and dystrophin analysis.

\section{References}

Arahata K, Hoffman EP, Kunkel LM, Ishiura S, Tsukahara T, Ishihara T, Sunohara N, Nonaka I, Ozawa E, Sugita H (1989) Dystrophin diagnosis: comparison of dystrophin abnormalities by immunofluorescence and immunoblot analyses. Proc Natl Acad Sci USA 86:7154-7158

Bakker E, Bonten EJ, De Lange LF, Veenema H, MajoorKrakauer D, Hofker MH, Ommen GJB van, Pearson PL (1986) DNA probe analysis for carrier detection and prenatal diagnosis of Duchenne muscular dystrophy: a standard diagnostic procedure. J Med Genet 23:573-580

Bakker E, Veenema H, Den Dunnen JT, Broeckhoven C van, Grootscholten PM, Bonten EJ, Ommen GJB van, Pearson PL (1989) Germinal mosaicism increases the recurrence risk for "new" Duchenne muscular dystrophy mutations. J Med Genet 26:553-559

Blonden LAJ, Den Dunnen JT, Paasen HMB van, Wapenaar MC, Grootscholten PM, Ginjaar HB, Bakker E, Pearson PL, Ommen GJB van (1989) High resolution deletion breakpoint mapping in the DMD gene by whole cosmid hybridization. Nucleic Acids Res 17:5611-5621
Bonilla E, Samitt CE, Miranda AF, Hays AP, Salviati G, DiMauro S, Kunkel LM, Hoffman EP, Rowland LP (1988) Duchenne muscular dystrophy: deficiency of dystrophin at the muscle cell surface. Cell 54:447-452

Chamberlain JS, Gibbs RA, Ranier JE, Caskey CT (1989) Multiplex PCR for diagnosis of Duchenne muscular dystrophy. In: Innis $\mathrm{M}$, Gelfand $\mathrm{D}$, Sninski J, White T (eds) PCR protocols: a guide to methods and applications. Academic Press, New York, pp 272-281

Chen J, Denton MJ, Morgan G, Pearn JH, Mackinlay AG (1988) The use of field-inversion gel electrophoresis for deletion detection in Duchenne muscular dystrophy. Am J Hum Genet 42: $777-780$

Cherif D, Bernard O, Berger R (1989) Detection of single-copy genes by nonisotopic in situ hybridization on human chromosomes. Hum Genet $81: 358-362$

Cremer T, Lichter P, Manuelidis L, Ward DC (1988) Detection of chromosome aberrations in metaphase and interphase tumor cells by in situ hybridization using chromosome-specific library probes. Hum Genet $80: 235-246$

Darras BT, Blattner P, Harper JF, Spiro AJ, Alter S, Francke U (1988) Intragenic deletions in 21 Duchenne muscular dystrophy (DMD)/Becker muscular dystrophy (BMD) families studied with the dystrophin cDNA: location of breakpoints on HindIII and $B g / I$ exon-containing fragment maps, meiotic and mitotic origin of the mutation. Am J Hum Genet 43:620-629

Davie AM, Emery AH (1978) Estimation of proportion of new mutants among cases of Duchenne muscular dystrophy. J Med Genet 15:339-345

Den Dunnen JT, Grootscholten PM, Bakker E, Blonden LAJ, Ginjaar HB, Wapenaar MC, Paassen HMB van, Broeckhoven C van, Pearson PL, Ommen GJB van (1989) Topography of the DMD gene: FIGE and cDNA analysis of 194 cases reveals 115 deletions and 13 duplications. Am J Hum Genet 45:835847

Hoffman EP, Brown RH, Kunkel LM (1987) Dystrophin: the protein product of the Duchenne muscular dystrophy locus. Cell 51: 919-928

Kievits T, Dauwerse JG, Devilee P, Breuning MH, Cornelisse CJ, Ommen GJB van, Pearson PL (1990) Rapid sub-chromosomal localization of cosmids by non-radioactive in situ hybridization. Cytogenet Cell Genet 53:134-136

Koenig M, Monaco AP, Kunkel LM (1988) The complete sequence of dystrophin predicts a rod-shaped cytoskeletal protein. Cell 53: 219-288

Koenig M, et al (1989) The molecular basis for Duchenne versus Becker muscular dystrophy: correlation of severity with type of deletion. Am J Hum Genet 45:498-506

Landegent JE, Jansen in de Wal N, Dirks RW, Baas F, Van der Ploeg M (1987) Use of whole cosmid cloned genomic sequences for chromosomal localization by non-radioactive in situ hybridization. Hum Genet 73:354-357

Langer PR, Waldrop AA, Ward DC (1981) Enzymatic synthesis of biotin-labeled polynucleotides: novel nucleic acid affinity probes. Proc Natl Acad Sci USA 78:6633-6637

Lichter P, Cremer T, Tang C-J C, Watkins PC, Manuelidis L, Ward DC (1988) Rapid detection of human chromosome 21 aberrations by in situ hybridization. Proc Natl Acad Sci USA $85: 9664-9668$

Lichter P, Tang C-JC, Call K, Hermanson G, Evans GA, Housman D, Ward DC (1990) High-resolution mapping of human chromosome 11 by in situ hybridization with cosmid clones. Science 247: 64-69

Love DR, Davis KE (1989) Duchenne muscular dystrophy: the gene and the protein. Mol Biol Med 6:7-17

Maniatis T, Fritsch EF, Sambrook J (eds) (1982) Molecular cloning: a laboratory manual. Cold Spring Harbor Laboratory, Cold Spring Harbor, NY

Mao Y, Cremer M (1989) Detection of Duchenne muscular carriers by dosage analysis using the DMD cDNA clone 8 . Hum Genet $81: 193-195$ 
Miranda AF, Francke U, Bonilla E, Martucci G, Schmidt B, Salviati G, Rubin M (1989) Dystrophin immunocytochemistry in muscle culture: detection of a carrier of Duchenne muscular dystrophy. Am J Med Genet 32:268-273

Moser H (1984) Duchenne muscular dystrophy: pathogenetic aspects and genetic prevention. Hum Genet $66: 17-40$

Nederlof PM, Van der Flier S, Wiegant J, Raap AK, Tanke HJ, Ploem JS, Van der Ploeg M (1990) Multiple fluorescence in situ hybridization. Cytometry $11: 126-131$

Pinkel D, Gray JW, Trask B, Van den Engh G, Fuscoe J, Van Dekken H (1986) Cytogenetic analysis with fluorescently labeled nucleic acid probes. Cold Spring Harb Symp Quant Biol 51: 151-157

Shapira F, Dreyfus JC, Shapira G, Démos J (1960) Etudes de l'aldolase et de la créatine kinase du sérum chez les méres de myopathes. Rev Fr Etudes Clin Biol 5:990-994
Speer A, Rosenthal A, Billwitz H, Hanke R, Forrest SM, Love D, Davies KE, Coutelle C (1989) DNA amplification of a further exon of DMD locus increases possibilities for deletion screening. Nucleic Acids Res 17:4892

Wapenaar MC, Kievits T, Hart KA, Abbs S, Blonden LAJ, Den Dunnen JT, Grootscholten PM, Bakker E, Verellen-Dumoulin C, Bobrow M, Ommen GJB van, Pearson PL (1988) A deletion hot spot in the Duchenne muscular dystrophy gene. Genomics 2: 101-108

Yang T, Hansen S, Oishi K, Ryder O, Hamkalo B (1982) Characterization of a cloned repetitive DNA sequence concentrated on the human X-chromosome. Proc Natl Acad Sci USA $79: 6593-6597$ 